\title{
ANALYSIS OF IGRP PERFORMANCE IN WDS MESH TOPOLOGY BASED ON IEEE 802.11 STANDARDS
}

\author{
Arief Ikhwan Wicaksono ${ }^{1}$, Chanief Budi Setiawan ${ }^{2}$ \\ ${ }^{1}$ Program Studi Teknologi Informasi, ${ }^{2}$ Program Studi Teknologi Informasi \\ Fakultas Teknik dan Teknologi Informasi, Universitas Jenderal Achmad Yani Yogyakarta \\ J1. Siliwangi Km 0.7, Banyuraden, Gamping, Sleman, Yogyakarta \\ 1awik@stmikayani.ac.id ${ }^{2}$ chanief.b.s@stmikayani.ac.id
}

\begin{abstract}
Redundancy and robustness are the most common problems in a wireless network distribution system, network system problems that are not able to handle coverage areas in a large / wide coverage, so that the network users are easily disconnected from the connection and out of the server radius. These problems are caused by topology and wireless network distribution methods that are not in accordance with the needs and coverage of its users. However, adding a number of access points en masse to expand the network without being based on appropriate applied methods, is not necessarily able to minimize complaints from network users. Starting from the problems described in the previous paragraph, in this study a wireless distribution mesh system topology (WDS mesh) will be built to improve utility and network usage in the area / radius of the area between access points using wireless lines and minimize cable requirements which are generally the main constraints in network deployment and installation to areas that are difficult to reach. The topology built in this research will implement the wireless routing protocol that results from the analysis and observation process to expand the expansion of service areas to places that are difficult to reach. The wireless routing protocol method used in this study is the Made Mesh Easy (MME) method which is one of the developments of the Interior Gateway Routing Protocol (IGRP) method. Evaluation of the wireless routing protocol in the WDS mesh network topology will be carried out periodically to obtain the results of the analysis that will be used to re-configuring and re-routing to maintain the quality of the network remains realiable. Mesh clients will give feedback on the quality of service obtained based on observations according to IEEE 802.11 standardization. The parameters used are: Througput, Packet Loss Ratio, Latency, Jitter, MOS, Post Dial Delay and Echo Cancelation (EC)
\end{abstract}

Keywords: WDS mesh, mesh, IGRP, jaringan, wireless routing protocol, QoS, IEEE 802.11

\section{Latar Belakang Masalah}

Kehadiran wireless telah berpengaruh terhadap perkembangan sistem pendistribusian jaringan. Wireless network memberikan kebebasan ruang kepada pengguna jaringan untuk dapat terhubung kedalamnya selama masih dalam cakupan akses point yang tersedia. Akan tetapi implementasi jaringan wireless masih membutuhkan node jaringan kabel sebagai penghubung akses point ke node backbone/server. Permasalah ini menjadi kendala untuk implementasi jaringan di tempattempat yang sulit dijangkau.

Redudancy dan robustless juga menjadi permasalahan yang paling sering muncul dalam sebuah sistem pendistribusian jaringan wireless, permasalahan sistem jaringan yang tidak mampu menangani coverage area dalam cakupan yang besar/luas, sehingga menyebabkan para pengguna jaringan mudah sekali terputus koneksinya dan keluar dari radius server. Pada umumnya masalah tersebut disebabkan oleh topologi dan metode pendistribusian jaringan wireless yang tidak sesuai dengan kebutuhan dan cakupan area para penggunanya. Namun, melakukan penambahan sejumlah akses point secara massal untuk melakukan ekspansi jaringan tanpa didasari oleh metode terapan yang tepat, belum tentu mampu meminimalisir keluhan para pengguna jaringan.

Bertolak dari permasalah yang diuraikan pada paragraf sebelumnya, pada penelitian ini akan dirancang dan dibangun testbed Wireless Distribution System mesh (WDS mesh) dengan menganalisa Interior Gateway Routing Protocol (IGRP) dan Made Mesh Easy (MME) sebagai 
metode wireless routing protocol-nya. Topologi WDS mesh dimanfaatkan untuk menyederhanakan pendistribusian jaringan dengan melakukan interkoneksi antar akses point menggunakan jalur wireless, serta meminimalisir kebutuhan kabel yang umumnya menjadi kendala utama dalam penyebaran dan instalasi jaringan ke area yang sulit dijangkau. Untuk meningkatkan utility dan penggunaan topologi WDS mesh, pada penelitian ini proses pemantauan interkoneksi beberapa mesh router dan mesh client dilakukan secara simultan dan periodik guna mendapatkan informasi dan konfigurasi untuk melakukan re-routing dan re-configuring metode wireless routing protocol yang lebih menjawab permasalahan yang ada. Untuk memudahkan dalam memodifikasi pekerjaan dengan spesifikasi wireless mesh network, pada wireless router mesh digunakan sebuah perangkat lunak mikrotik routerOS sebagai sistem operasinya. Penelitian ini menggunakan standarisai Quality of Services (QoS) yang mengacu pada ITU G.165 / G.168. Paramenter yang digunakan dalam pengukuran interkoneksi mesh client dengan mesh router diantaranya : Througput, Packet Loss Ratio, Latency, Jitter, MOS, Post Dial Delay dan Echo Cancelation (EC).

\section{Metodologi Penelitian}

Penelitian ini merupakan penelitian pengembangan (research development) yang bertujuan untuk mengembangkan topologi jaringan secara wireless ditribution mesh pada layanan topologi yang sudah berjalan. Metode pengumpulan data dan informasi yang dilakukan adalah dengan menggunakan metode studi pustaka, wawancara dan observasi. Metode pengembangan topology yang digunakan adalah metode agile development. Metode agile development dipilih karena user dari WDS mesh yang dikembangkan nantinya adalah pengguna jaringan yang membutuhkan perubahan desain, implementasi topologi dan perbaikan secara cepat sehingga model pengembangan topologi jaringan secara iterative tepat untuk digunakan. Segala bentuk masukkan dari user juga akan langsung diimplementasikan secara cepat dan diuji coba ulang. Secara garis besar dalam proses iterasinya, agile development terdiri dari 4 tahapan (Pressman, 2010)

Tabel 1 Tahapan metode agile development

\begin{tabular}{|l|l|l|l|}
\hline No & \multicolumn{1}{|c|}{ Tahap } & \multicolumn{1}{|c|}{ Langkah } & \multicolumn{1}{|c|}{ Indikator } \\
\hline 1 & $\begin{array}{l}\text { Identifikasi } \\
\text { dan analisis } \\
\text { kebutuhan }\end{array}$ & $\begin{array}{l}\text { a) Melakukan konfigurasi dan uji coba } \\
\text { pemasangan basic wireless } \\
\text { b) Membuat rencana pemetaan wilayah } \\
\text { layanan jaringan untuk melakukan } \\
\text { simulasi pendistribusian (mapping) }\end{array}$ & $\begin{array}{l}\text { a) Tempat-tempat yang sulit dijangkau } \\
\text { jaringan kabel yang akan digunakanan } \\
\text { dalam penelitian berhasil ditentukan } \\
\text { b) Pemetaan pendistribusian jaringan } \\
\text { bisa secara real menjelaskan cakupan } \\
\text { area-area yang akan dijangkau }\end{array}$ \\
\hline 2 & Desain sistem & $\begin{array}{l}\text { a) Mengembangkan desain topologi } \\
\text { jaringan berdasarkan hasil pemetaan } \\
\text { sebelumnya } \\
\text { b) Melakukan uji coba dan pengambilan } \\
\text { data kualitas WDS mesh dalam interval } \\
\text { waktu yang ditentukan }\end{array}$ & $\begin{array}{l}\text { a) Perangkat wireless sudah mampu } \\
\text { mencover tempat-tempat yang sulit } \\
\text { dijangkau jaringan kabel } \\
\text { b) Mesh server dan mesh client sudah } \\
\text { berhasil terhubung dan berjalan dengan } \\
\text { baik }\end{array}$ \\
\hline 3 & $\begin{array}{l}\text { Implentasi } \\
\text { Sistem }\end{array}$ & $\begin{array}{l}\text { jaringan WDS mesh sebagai routing } \\
\text { protocol }\end{array}$ & $\begin{array}{l}\text { Protokol IGRP dapat berjalan pada } \\
\text { jaringan WDS mesh sesuai dengan } \\
\text { tujuan penelitian, dengan indikator sbb : } \\
\text { a) Pengamatan Qos menunjukan nilai } \\
\text { baik } \\
\text { b) Wireless router dapat terhubung } \\
\text { dengan baik dengan mesh client dan } \\
\text { mesh router } \\
\text { c) Memperoleh data yang berasal dari } \\
\text { nilai pengamatan QoS secara periodik } \\
\text { sebagai feedback untuk melakukan re- }\end{array}$ \\
\hline
\end{tabular}




\begin{tabular}{|l|l|l|l|}
\hline 4 & $\begin{array}{l}\text { Pengujian } \\
\text { Sistem }\end{array}$ & $\begin{array}{l}\text { a) Melakukan pengujian akhir pada } \\
\text { topologi yang dibangun. Dengan menguji } \\
\text { semua fungsionalitas } \\
\text { b) Penggunaan parameter QoS berdasar }\end{array}$ & routing dan re-configuring \\
& & $\begin{array}{l}\text { standarisasi IEEE } 802.11 \text { untuk } \\
\text { memberikan feedback atas kualitas link } \\
\text { antara mesh client dengan mesh router }\end{array}$ & \\
\hline
\end{tabular}

\subsection{Arsitektur Kerja Sistem}

Arsitektur sistem yang dibangun pada penelitian ini terbagi kedalam beberapa node topologi yaitu WDS, MESH, WDS MESH, Preprocessing, dan QoS Analisis IGRP

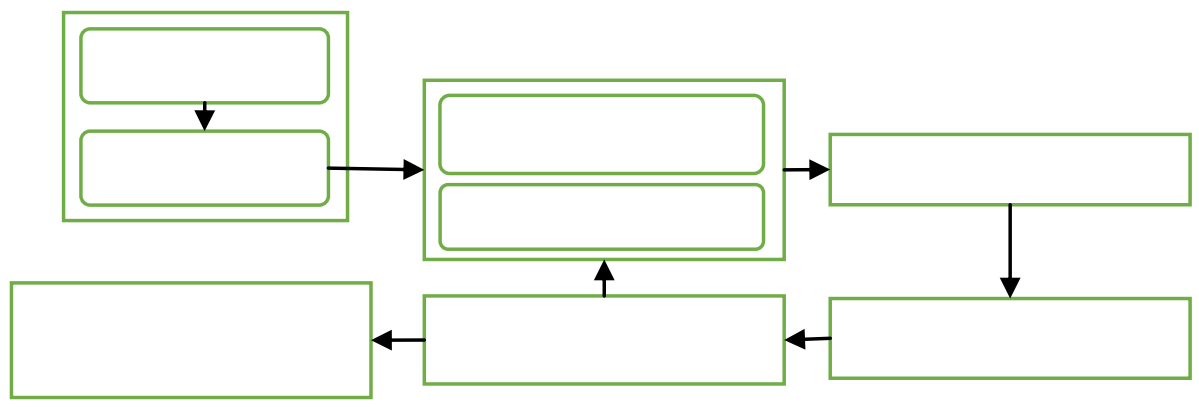

Gambar 1 Rancangan arsitektur sistem.

Penjelasan dari tiap-tiap bagian pada arsitektur sistem yang ditunjukan oleh gambar 2 adalah sebagai berikut :

1. WDS mode. Pada bagian ini berfungsi sebagai pengambilan keputusan terhadap settingan WDS yang nantinya akan dirancang, dan selanjutnya mengimplementasikan fitur mesh pada infrastruktur jaringan yang sedang berjalan. Dalam tahapan ini, diantaranya termasuk mempertimbangkan peletakan access point yang nantinya akan diproyeksikan dapat berkomunikasi sesama mesh node berdasarkan : masukan dari user pengguna layanan jaringan, konstruksi gedung/bangunan, dan instalasi jaringan sumber daya kelistrikan. Disamping masalah konstruksi gedung dan infrastruktur jaringan listrik sebagai daya untuk menyalakan akses point, hasil monitoring terhadap konektivitas sesama mesh node yang berjalan juga perlu digunakan sebagai masukan pada tahap perancangan ini.

2. Pemilihan bridge / mesh interface sebagai topologi utama dalam penelitian ini bertujuan untuk menentukan metode mana yang paling pas bila dihadapkan dengan hasil monitoring kestabilan sebuah node. Beberapa faktor penunjang kestabilan node adalah banyak tidaknya halangan yang bersifat dinamis, baik itu konstruksi instalasi listrik maupun kestabilan daya dalam gedung tersebut.

3. Preprocessing berfungsi untuk mempersiapkan kualitas hubungan yang terbentuk oleh wds mesh dari dan ke mesh portal/master. Pemilihan access point sebagai wds mesh portal ditekankan pada bagian ini, sehingga node yang berada ditengah-tengah topologi wireless distribustion diutamakan untuk didesain sebagai mesh portal.

4. Interface selection digunakan untuk menentukan mesh/bridge interface, setelah melalui proses pengamatan secara mandiri.

5. Monitoring didapatkan ketika proses pertukaran data sudah mencapai nilai ideal, kemudian proses pemilihan dilakukan kembali jika belum menemukan konfigurasi yang paling baik.

6. Setelah proses monitoring antar node selesai, barulah pengamatan Quality of Services dari protokol IGRP dilakukan. Pengambilan data dalam bentuk CSV (Comma Seperated Value) dikumpulkan secara periodik, dari data tersebut akan diamati dan dianalisa untuk memperoleh hasil kinerja protokol IGRP pada jaringan WDS berdasarkan standar QoS yang akan digunakan. 


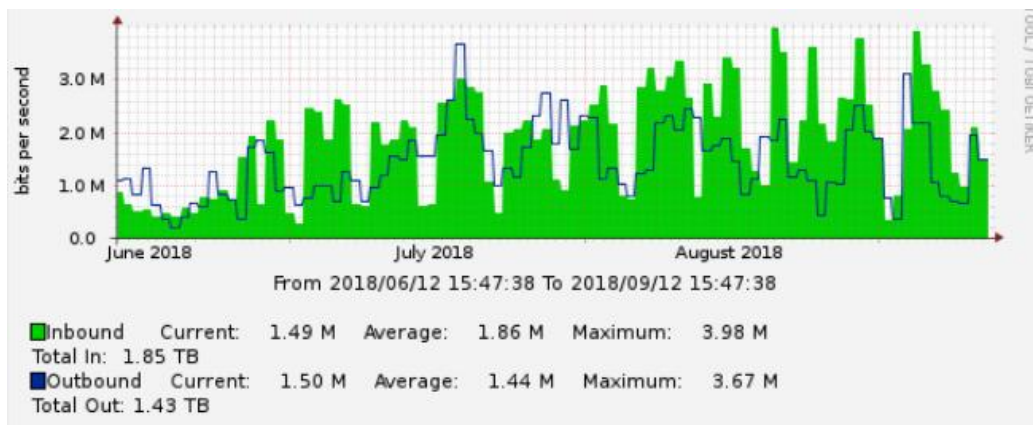

Gambar 2 Hasil monitoring jaringan WDS sejak juni hingga september.

Dari pegamatan grafik pada gambar 3, didapatkan data CVS (Comma Seperated Value) yang dapat dijabarkan kedalam bentuk tabel, kemudian dari data tersebut dapat digunakan untuk menghitung nilai rata-rata dan SD (standar deviasi) untuk tiap-tiap parameter QoS yang akan digunakan untuk menganalisa protokol IGRP, diantaranya adalah : Througput, Packet Loss Ratio, Latency, Jitter, MOS, Post Dial Delay dan Echo Cancelation (Wicaksono, A. I., \& Azhari, S. N, 2011).

Tabel 2 Nilai skor pengamatan parameter QoS dari WDS master ke WDS slave

\begin{tabular}{|c|c|c|c|c|c|}
\hline \multirow{2}{*}{ No } & \multirow{2}{*}{ Parameter } & \multicolumn{4}{|c|}{ Analisis QoS terhadap protokol IGRP } \\
\cline { 3 - 6 } & & $\mathrm{M} \rightarrow(\mathrm{S} 1)$ & $\mathrm{M} \rightarrow \mathrm{S} \mathrm{2}$ & $\mathrm{M} \rightarrow \mathrm{S} 3$ & $\mathrm{M} \rightarrow \mathrm{S} 4$ \\
\hline 1 & Throughput & 90,2 & 93,3 & 83,6 & 83,5 \\
\hline 2 & PLR & 0 & 0 & 0 & 0 \\
\hline 3 & Delay & 55,1 & 34,5 & 24,5 & 16,4 \\
\hline 4 & Jitter & 0 & 0 & 0 & 0 \\
\hline 5 & Latency & 0.1 & 0.2 & 0.1 & 0.1 \\
\hline 6 & PDD \& EC & 0 & 0 & 0.1 & 0 \\
\hline
\end{tabular}

\subsection{Proses Bisnis yang Berjalan}

Gambar 3 berikut ini menunjukan topologi jaringan yang berjalan (as-is-bussiness process). Pemodelan ini bertujuan untuk memetakan aliran bandwidth dan mengidentifkasi kelemahankelemahan yang ada.

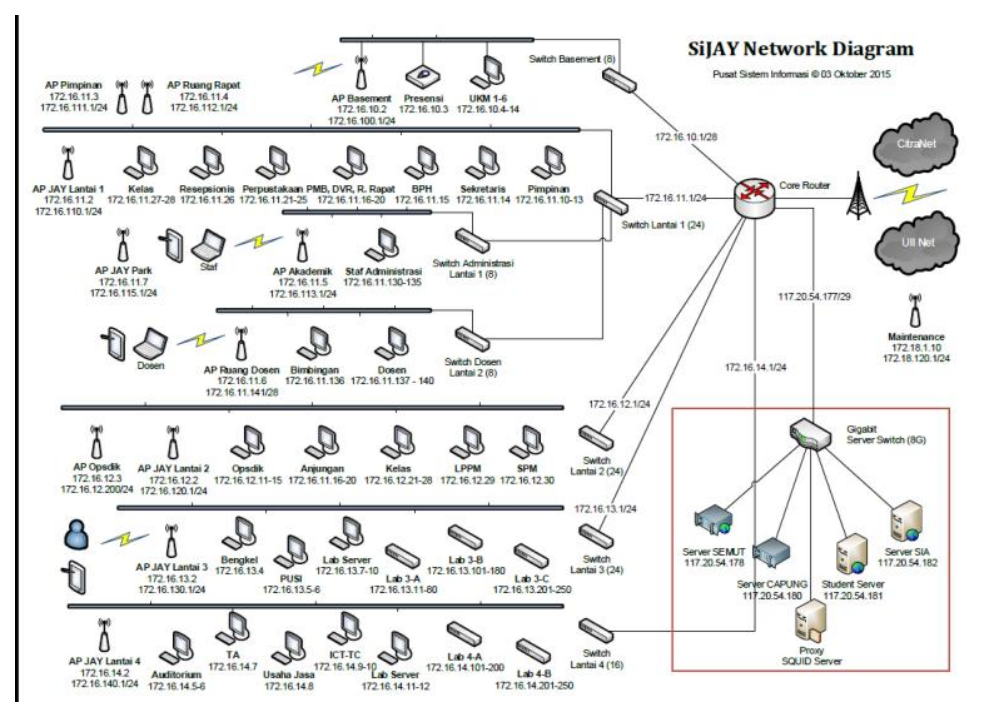

Gambar 3. Kondisi Topologi yang Berjalan

Pada proses bisnis tersebut secara visual nampak bahwa node access point memiliki nilai dependency yang tinggi terhadap node switch perlantai, node switch atau yang bisa disebut dengan distribution node memegang peranan penting dalam pendistribusian jaringan wireless. Jika terdapat permintaan untuk melebarkan kemampuan coverage area via wireless, maka penambahan access 
point pun menuntut penambahan tatanan kabel baru agar dapat meletakkannya di lokasi permintaan tersebut. Pengukuran efektifitas kemampuan kabel dalam mengirim data/bandwidht pun memerlukan perhitungan yang terukur agar nilai loss dapat ditekan.

Hasil pengukuran nilai packet loss ratio bisa terlebih dahulu dicari dengan satuan bps (Kalamani, P., Kumar, M. V., et.al., 2014). Throughput (bps) $=\frac{\sum \text { data yang dikirim (bit) }}{\text { waktu pengiriman data (s) }}$ kemudian secara periodik data pengamatan tersebut dicatat secara berkala dan terukur ke dalam datasheet. Nilai tersebut sangat berpengaruh pada waktu pendistribusian jaringan nantinya. Penentuan nilai terbaik diambil menggunakan perhitungan standar deviasi. Proses penambahan akses point yang terhubung pada distribution node (switch) membutuhkan waktu kurang lebih $2-3$ jam termasuk perhitungan dan instalasi kabel lan.

\subsection{Rekayasa Ulang Proses Bisnis}

Berdasarkan pada temuan-temuan inefisiensi dan kelemhan pada proses bisnis berjalan (asis) seperti yang diuraikan pada bagian 3.1, maka dalam bagian ini diuraikan proses bisnis yang baru untuk memperbaiki kelemahan tersebut. Dalam proses bisnis baru yang ditunjukan pada gambar 4 .
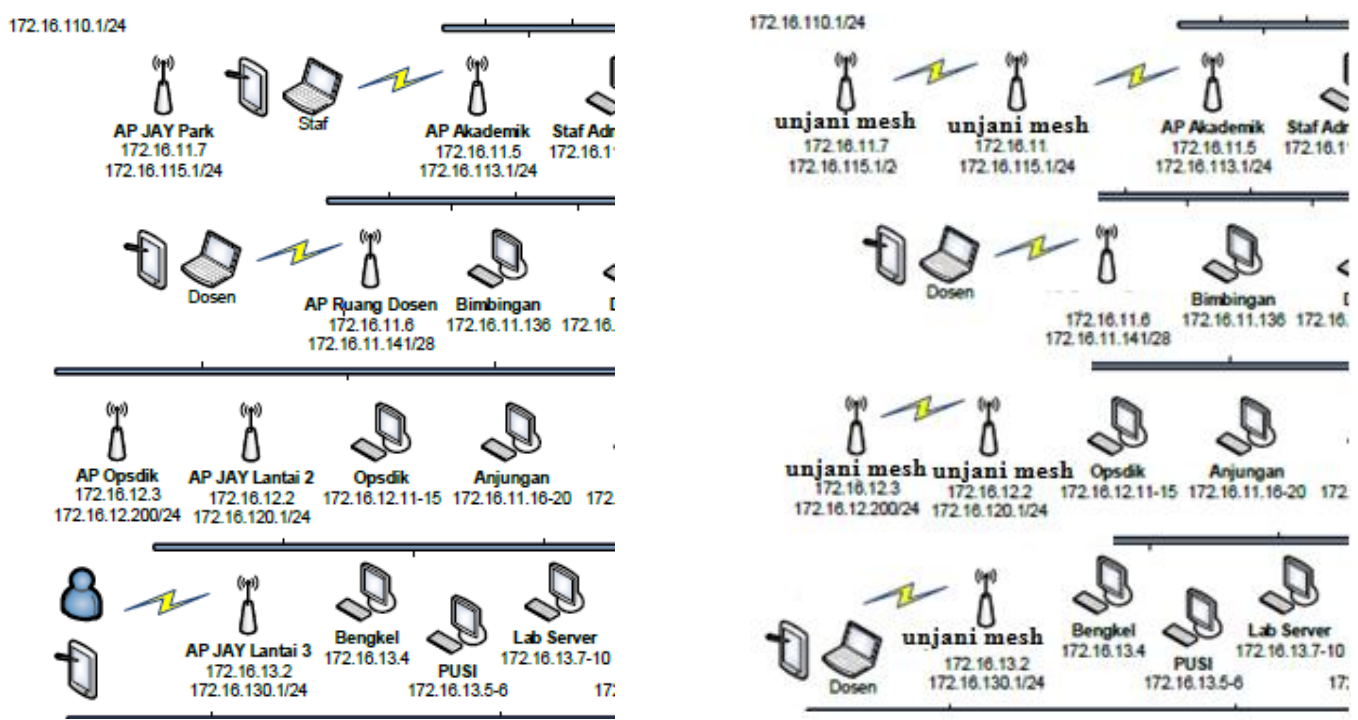

Gambar 4. Perubahan topologi jaringan WDS pada node terakhir.

Distribusi jaringan sebelumnya tergantung dengan keberadaan node kabel yang menghubungkan antara access point dengan distribution node yang kemudian dirubah menggunakan node wireless dalam topologi distribution system nya. Penentuan kualitas wireless distribution sangat dipengaruhi oleh proses monitoring dalam mendapatkan kualitas yang paling baik. Secara lebih detail proses monitoring dilakukan berdasarkan pengamatan secara berkala berdasarkan parameter throughput antara mesh master dengan mesh slave. Ketergantungan akan besar signal yang diterima dari dan ke mesh interface maupun bridge interface dijadikan pertimbangan untuk menentukan interface mana yang akan dipilih agar dapat diproses ke dalam tahap selanjutnya. Setelah proses processing selesai maka proses selanjutnya adalah monitoring secara lebih mendetail terhadap kualitas yang didapatkan antara mesh node dan mesh master berdasarkan pengamatan quality of service yang merujuk pada ITU G.165 / G.168.

\subsection{QoS Mesh Protokol IGRP}

Pengamatan layanan WDS mesh memanfaatkan protokol IGRP dilakukan secara periodik dan berkala, diantara parameter-parameter yang diamati dalam penelitian ini adalah Througput, Packet Loss Ratio, Latency, Jitter, MOS, Post Dial Delay dan Echo Cancelation (Lara-Cueva, R., Benítez, D., et. al, 2015) Nilai pengamatan tersebut kemudian diolah dalam rancangan model konseptual evaluasi sistem pendistribusian jaringan. Secara lebih detail, poin evaluasi topologi 
pendistribusian jaringan memanfaatkan wireless distribution system yang berjalan dijabarkan sebagai berikut :

1. Data record QoS yang berasal dari mesh master menuju mesh slave diambil untuk menentukan WDS dapat berjalan dengan kualitas yang baik

2. Data record QoS yang berasal dari mesh slave kembali ke mesh master diambil untuk menentukan acuan dalam proses tata kelola dan evaluasi pendistribusian jaringan.

3. Data record tambahan yaitu data record QoS yang berasal dan menuju antara node client / pengguna dengan mesh slave digunakan untuk pertimbangan pengelolaan jaringan.

Pada bagian evaluasi yang dilakukan pada gambar 5. Dapat diketahui bahwa proses pendistribusian jaringan diharapkan mampu memperluas coverage area pendistribusian jaringan. Pada proses evaluasi tersebut pengamatan jaringan disajikan ke dalam bentuk grafik sehingga mampu membantu untuk meningkatkan sistem tata kelola pendistribusian jaringan dalam menjangkau area-area yang sebelumnya tidak ter-cover.

\section{Hasil dan Pembahasan}

\subsection{Implementasi Topologi WDS}

Hasil pengamatan dari tabel perbandingan QoS yang diperoleh setelah implementasi WDS sangat bervariasi, hal ini dipengaruhi oleh banyak faktor, diantaranya meliputi delay yang terjadi ketika mengakses situs melalui topologi tersebut, hal ini terjadi secara umum dikarenakan mesh master dan mesh slave akan selalu mengalami interferensi pada saat pengoperasiannya. faktor utama yang mempengaruhi interference value adalah tingkat kerapatan channel wireless yang ada.

Nilai pengamatan parameter QoS yang dihasilkan pada packet loss, latency, jitter, dan MOS juga sangat bervariasi ketika dalam pengujiannya, hal ini disebabkan oleh kondisi transmit / receive yang berbeda antara wireless distribution dan cabling distribution. WDS dalam pengoperasiannya secara otomatis membagi throughput jaringan yang tersedia kedalam 2 bagian, bagian pertama digunakan sebagai distribution link traffic, dan setengah bagian yang lain digunakan untuk distribution data traffic. Sehingga menyebabkan terjadinya congestion dan drop pada sebagain paket paket yang lewat pada topologi jaringan tersebut.

Implementasi pendistribusian jaringan dapat dilihat pada gambar 5. Mesh master dan mesh slave mendistribusikan jaringan secara wireless dengan satu SSID yang sama, dengan kata lain header MAC address pengguna dari paket traffic tidak berubah antar link access point meskipun berpindah posisi, sehingga pengamatan nilai post dial delay dan echo cancelaction dapat dilakukan secara roaming.

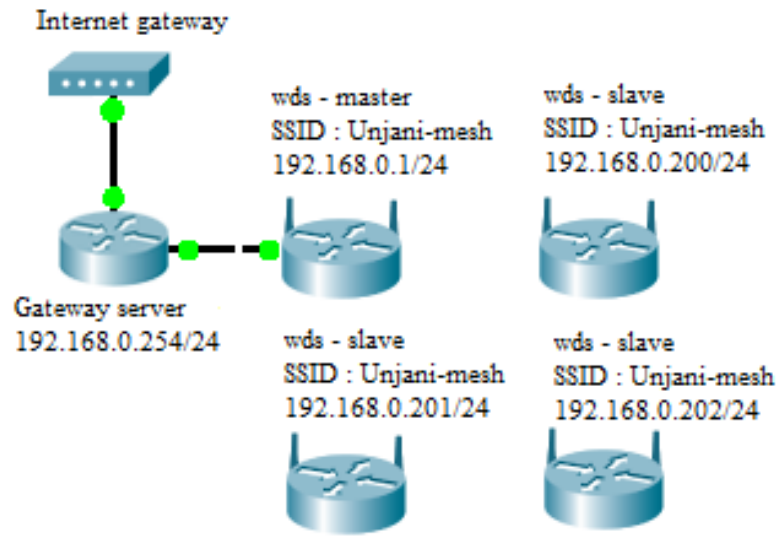

Gambar 5. Topologi jaringan WDS 


\begin{tabular}{|l|l|l|l|l|}
\hline 1 & $\mathrm{M} \leftarrow \rightarrow \mathrm{S} 1$ & 55,1 & 4 & Sangat Bagus \\
\hline 2 & $\mathrm{M} \leftarrow \rightarrow \mathrm{S} 2$ & 34,5 & 4 & Sangat Bagus \\
\hline 3 & $\mathrm{M} \leftarrow \rightarrow \mathrm{S} 3$ & 24,5 & 4 & Sangat Bagus \\
\hline 4 & $\mathrm{M} \leftarrow \rightarrow \mathrm{S} 4$ & 16,4 & 4 & Sangat Bagus \\
\hline
\end{tabular}

Rekapitulasi nilai QoS antar node untuk kategori nilai "Sangat Memuaskan”. Dengan kategorisasi sebagai berikut : "Memuaskan" jika nilai QoS 3 - 3,79, "Kurang Memuaskan" jika nilai QoS 2 2,99 dan "Jelek" jika nilai QoS 1 - 1,99 sesuai dengan Tabel 7.

Tabel 7 Pengukuran Parameter QoS

\begin{tabular}{|l|l|l|l|}
\hline No & Lokasi & Nilai & Kategori \\
\hline 1 & $\mathrm{M} \leftarrow \rightarrow \mathrm{S} 1$ & 3,8 & Memuaskan \\
\hline 2 & $\mathrm{M} \leftarrow \rightarrow \mathrm{S} 2$ & 3,75 & Memuaskan \\
\hline 3 & $\mathrm{M} \leftarrow \rightarrow \mathrm{S} 3$ & 3,25 & Memuaskan \\
\hline 4 & $\mathrm{M} \leftarrow \rightarrow \mathrm{S} 4$ & 4,00 & Memuaskan \\
\hline
\end{tabular}

Rekapitulasi hasil pengukuran dapat dilihat pada tabel 8, yaitu :

1. Packet loss : hasil pengukuran packet loss untuk masing-masing host adalah $0 \%$ menurut standar ITU G.165 / G.168 jika rata-rata packet loss 0\% maka masuk kedalam kategori "Sangat Bagus".

2. Delay/latency : hasil pengukuran delay/latency untuk masing-masing host adalah tertinggi terdapat di node master mesh - mesh slave 4, dengan nilai $16,4 \mathrm{~ms}$ sedangkan terendah terdapat di node master mesh - mesh slave 1 dengan nilai 55,1 ms menurut standar ITU G.165 / G.168 jika rata-rata delay/latency $<150$ ms maka masuk kedalam kategori "Sangat Bagus".

3. Jitter : hasil pengukuran jitter untuk masing-masing host adalah $0 \mathrm{~ms}$ menurut standar ITU G.165 / G.168 jika rata-rata jitter 0 ms maka masuk kedalam kategori "Sangat Bagus".

4. Throughput : hasil pengukuran throughput untuk masing-masing gedung adalah tertinggi terdapat di node master mesh - mesh slave 2 dengan nilai 93,3 masuk kedalam kategori "Sangat Bagus" sedangkan nilai indeks terendah terdapat di host Sijay Park dan Peneliti dengan nilai 20,50 masuk kedalam kategori "Jelek".

Tabel 8 Rekapitulasi hasil pengukuran QoS

\begin{tabular}{|l|l|l|l|l|l|}
\hline \multirow{2}{*}{ No } & \multirow{2}{*}{ Parameter } & \multicolumn{4}{|l|}{ Analisis QoS } \\
\cline { 3 - 6 } & & $\mathrm{M} \leftarrow \rightarrow \mathrm{S} 1$ & $\mathrm{M} \leftarrow \rightarrow \mathrm{S} 2$ & $\mathrm{M} \leftarrow \rightarrow \mathrm{S} 3$ & $\mathrm{M} \leftarrow \rightarrow \mathrm{S} 4$ \\
\hline 1 & Throughput & 90,2 & 93,3 & 83,6 & 83,5 \\
\hline 2 & PLR & 0 & 0 & 0 & 0 \\
\hline 3 & Delay & 55,1 & 34,5 & 24,5 & 16,4 \\
\hline 4 & Jitter & 0 & 0 & 0 & 0 \\
\hline
\end{tabular}

Hasil pengukuran QoS didapat nilai untuk antar host sebagai berikut : untuk troughput tertinggi tercatat pada host master mesh - mesh slave 2 dengan nilai 93,3 dan terendah pada master mesh mesh slave 4 dengan nilai 83,5. Sedangkan Packet Loss Ratio rata-rata memiliki nilai kategori bagus/memuaskan. Pengukuran delay juga memperlihatkan bahwa yang tertinggi adalah master mesh - mesh slave 1 dan master mesh - mesh slave 2, sedangkan untuk master mesh - mesh slave lain masih tetap baik/memuaskan.

\section{Kesimpulan}

Topologi WDS dapat digunakan untuk memperluas coverage area ke tempat-tempat yang sulit dijangkau oleh instalasi kabel, proses enkripsi dan enkapsulasi antar node slave dapat digunakan untuk memastikan bahwa proses hand shaking tidak terlepas jika ada kesalahan node registration yang terhubung dalam mesh table. Sehingga manfaat yang dapat dirasakan adalah kualitas wireless distribution dapat berjalan dengan baik. Dengan memanfaatkan metode distribusi HWMP+ (Hybrid Wireless Mesh Protocol) maka distribusi pada layer 2 sesuai rancangan standar IEEE 802.11s dapat 
mengadaptasi metode protokol IGRP dalam pendistribusiannya. Sehingga layanan wireless user roaming dapat berjalan dengan memuaskan.

Manfaat yang diterima oleh wireless user WDS diantaranya adalah : bebas trafik looping, optimalisasi jalur routing berdasarkan perhitungan path cost, dan aktualisasi bandwidth yang diperolah masing-masing client node dengan hasil pengukuran QoS didapat nilai untuk antar host sebagai berikut : untuk troughput tertinggi tercatat pada host master mesh - mesh slave 2 dengan nilai 93,3 dan terendah pada master mesh - mesh slave 4 dengan nilai 83,5. Sedangkan Packet Loss Ratio rata-rata memiliki nilai kategori bagus/memuaskan. Pengukuran delay juga memperlihatkan bahwa yang tertinggi adalah master mesh - mesh slave 1 dan master mesh - mesh slave 2, sedangkan untuk master mesh - mesh slave lain masih tetap baik/memuaskan.

\section{Daftar Pustaka}

[1] Lara-Cueva, R., Benítez, D., Fernández, C., \& Morales, C. (2015, July). Performance Analysis of Wireless Network Modes in Conformance with IEEE 802.11 b and WDS. In Computer Aided System Engineering (APCASE), 2015 Asia-Pacific Conference on (pp. 370-373). IEEE.

[2] Kalamani, P., Kumar, M. V., et.al. (2014). Comparison of RIP, EIGRP, OSPF, IGRP Routing Protocols in Wireless Local Area Network (WLAN) by using OPNET Simulator tool-A Practical Approach. IOSR Journal of Computer Engineering (IOSR-JCE).

[3] Pressman, R. S. (2005). Software engineering: a practitioner's approach. Palgrave Macmillan.

[4] Wicaksono, A. I., \& Azhari, S. N. (2011). KOMPARASI METODE LOAD BALANCING DAN REKOMENDASINYA (Doctoral dissertation, Universitas Gadjah Mada). 